\title{
Strategi Komunikasi Lingkungan Membangun Kesadaran Masyarakat Terhadap Kebersihan Sungai Jagir
}

\author{
Arkansyah, Edelwies Putri Prima, Wiwin PA, Ananda ACP, Gabriela NVM, Arman DP \\ Sekolah Tinggi Ilmu Komunikasi Almamater Wartawan Surabaya . \\ Jalan Nginden Intan Timur I / 18 Surabaya \\ Email: arkansyah@stikosa-aws.ac.id
}

\begin{abstract}
The existence of Kali Jagir Surabaya is important for the sustainability of the economy and the life of the people, industry and commerce around the riverbanks. Water from Kali Jagir becomes the source for PDAM Surabaya which is processed into drinking water automatically depending on the condition of water quality. For the residents of the Jagir River, they are expected to have a role in maintaining the cleanliness of the river and the surrounding environment. The implementation of this community service seeks to build community awareness regarding the river environment which is the main source of human life through the application of environmental communication and how communication strategies are implemented. This awareness needs to be done collectively to jointly protect the environment in order to reduce damage and decrease environmental quality. Researchers used a survey method with the application of descriptive qualitative studies, namely researchers conducted interviews and observations by going into the field to examine the condition of the object and understand social phenomena from a natural point of view. In the implementation of community service, researchers produced infographic media products in the form of information banners on the Jagir river water pollution to residents in related locations.
\end{abstract}

Key words: environmental communication, water quality Kali Jagir Surabaya, environment, communication strategy

\section{Abstrak}

Keberadaan kali jagir Surabaya penting untuk keberlangsungan perekonomian dan hidup masyarakat, industri, dan niaga di sekitar bantaran kali. Air dari kali jagir menjadi sumber untuk PDAM Surabaya yang di olah menjadi air konsumsi minum secara otomatis juga bergantung pada kondisi kualitas air. Untuk warga stren kali Jagir, diharapakan mempunyai peran untuk menjaga kebersihan sungai dan lingkungan sekitar. Pelaksanaan pengabdian masyarakat ini berupaya untuk membangun kesadaran warga terkait lingkungan sungai yang menjadi sumber utama kehidupan manusia melalui penerapan komunikasi lingkungan dan bagaimana strategi komunikasi dilaksanakan. Pada kesadaran tersebut perlu dilakukan secara kolektif untuk bersama menjaga lingkungan hidup agar mengurangi kerusakan dan penurunan kualitas lingkungan. Peneliti menggunakan metode survei dengan penerapan studi kualitatif deskriptif yakni peneliti melakukan wawancara dan observasi dengan terjun ke lapangan untuk meneliti kondisi objek dan memahami fenomena sosial dari sudut pandang secara alami. Dalam pelaksanaan pengadian masyarakat, peneliti menghasilkan produk media infografis berupa banner informasi pencemaran air sungai Jagir kepada warga di lokasi terkait.

Kata kunci : komunikasi lingkungan, kualitas air kali jagir surabaya, lingkungan hidup, strategi komunikasi 


\section{PENDAHULUAN}

Sungai adalah aliran air yang mengalir secara besar dan memanjang dan terus-menerus mengalir dari hulu (sumber) menuju hilir (muara). Sungai juga merupakan salah satu bagian dari proses hidrologi. Secara alami, sungai adalah sumber kehidupan bagi lingkungan di sekitarnya baik manusia, hewan dan tumbuhan. Sungai di Surabaya telah mengalami penurunan kualitas yang disebabkan banyak faktor, Berdasarkan Supratiwi (2014) bahwa sekitar 60 hingga 70 persen pencemaran sungai disebabkan oleh limbah domestik, sedangkan limbah yang dapat diolah hanya 6,1 persen. Walaupun penurunan pencemaran sungai akibat limbah industri telah mencapai 40 persen, tingginya kontribusi limbah rumah tangga menyebabkan sungai masih terus tercemar. Perilaku manusia yang tidak bertanggung jawab terhadap sampah dapat menyebabkan munculnya masalah dan kerusakan lingkungan. Bila perilaku manusia semata-mata mengarah lebih pada kepentingan pribadinya, dan kurang atau tidak mempertimbangkan kepentingan umum / kepentingan bersama, maka dapat diprediksi bahwa daya dukung lingkungan alam semakin terkuras habis dan akibatnya kerugian dan kerusakan lingkungan tak dapat dihindarkan lagi.

Kali Jagir digunakan untuk keperluan domestik salah satunya sebagai air baku minum yang dikelola oleh PDAM Surya Sembada. Sesuai dengan PP No.82 Tahun 2001 tentang Pengelolaan Kualitas Air dan Pengendalian Pencemaran Air, maka klasifikasi mutu air ditetapkan menjadi 4 (empat) kelas : Kelas I, yaitu air yang peruntukannya dapat digunakan untuk air baku air minum, dan atau peruntukan lain yang mensyaratkan mutu air yang sama dengan kegunaan tersebut. Kelas II, yaitu air yang peruntukannya dapat digunakan untuk sarana/prasarana rekreasi air, pembudidayaan ikan air tawar dan air payau, peternakan, air untuk mengairi pertamanan, dan/ atau peruntukan lain yang mensyaratkan mutu air yang sama dengan kegunaan tersebut. Kelas III, yaitu air yang peruntukannya dapat digunakan untuk pembudidayaan ikan air tawar dan air payau, peternakan, air untuk mengairi pertamanan, dan/atau peruntukan lain yang mensyaratkan mutu air yang sama dengan kegunaan tersebut. Kelas IV, air yang peruntukannya dapat digunakan untuk mengairi pertamanan dan/atau peruntukan lain yang mensyaratkan mutu air yang sama dengan kegunaan tersebut.

Salah satu sumber utama pencemaran sungai jagir kota Surabaya berasal dari pembuangan sampah di sekitaran sungai dan ada yang sudah masuk ke sungai. Sampah mengganggu estetika kawasan tepian sungai. Selain itu, sampah juga menjadi tempat berkembangnya berbagai macam penyakit, mengurangi kenyamanan dan menimbulkan banjir. Sampah sebagai pencemar di sungai dapat mengakibatkan sungai menjadi dangkal. Kondisi ini secara otomatis mempengaruhi rantai makanan dan ekosistem yang ada di sungai. Kurangnya edukasi dan penyuluhan menyebabkan kebiasaan buruk ini terus menerus dilakukan. Maka dengan kondisi kampung yang menengah ke bawah dan tidak memiliki perangkat desa

Menurut Entjang (1987), Sampah adalah zat-zat atau benda-benda yang tidak dipakai lagi, baik berasal dari rumah tangga maupun sisa-sisa industri. Dalam pengertian lain sampah adalah segala sesuatu yang tidak dikehendaki oleh yang punya dan bersifat padat, ada yang mudah membusuk terutama sampah yang terdiri dari zat-zat organik seperti sisa sayuran, sisa daging, daun dan sebagainya. Sedangkan yang tidak dapat membusuk dapat berupa kertas, karet, logam, kaca, plastik, dan sebagainya (Slamet, 1994).

Sehubung dengan hal diatas, maka Leonardo (1990) mengatakan bahwa limbah padat merupakan salah satu bentuk limbah yang terdapat di lingkungan masyarakat, orang awam menyebutnya dengan sampah. Sampah dan kesehatan lingkungan sebenarnya hanya sebagian dari benda atau hal-hal yang dipandang tidak dapat digunakan lagi, tidak dipakai tidak 
disenangi, atau harus dibuang sedemikian rupa sehingga tidak sampai mengganggu kelangsungan hidup.

Oleh karena itu diperlukan strategi komunikasi lingkungan kepada masyarakat agar mereka menyadari dan merasa memiliki tanggung jawab terhadap lingkungan untuk mengelola serta melestarikan alam sekitar dan memanfaatkan potensi-potensi yang ada.

Komunikasi lingkungan adalah sarana pragmatis dan konstitutif untuk memberikan pemahaman mengenai lingkungan kepada masyarakat, seperti halnya hubungan kita dengan alam semesta. Ini merupakan sebuah media simbolik yang digunakan untuk menciptakan masalah lingkungan dan negosiasi perbedaan respon terhadap permasalah lingkungan yang terjadi. Dengan kata lain komunikasi lingkungan digunakan untuk menciptakan kesepahaman mengenai permasalahan lingkungan (Cox, 2010:20). Menyangkut srategi pengemasan pesan dalam media untuk menumbuhkan kesadaran dan partisipasi masyarakat dalam pengelolaan lingkungan. Komunikator utama dalam komunikasi lingkungan adalah pemerintah dan organisasi non pemerintah yang punya komitmen terhadap pengelolaan lingkungan.

Pada dasarnya komunikasi lingkungan untuk menumbuhkan kesadaran dan partisipasi masyarakat dalam mengelola lingkungan termasuk hutan dan polanya bersifat dialogis yang lebih banyak terjadi pada komunikasi interpersonal dan komunikasi kelompok. Partisipasi masyarakat itu salah satunya dapat ditumbuhkan melalui komunikasi lingkungan karena mulai dari unsur, media dan prosesnya bertujuan untuk menumbuhkan partisipasi masyarakat dalam mengelola hutan, atau dengan kata lain komunikasi lingkungan merupakan media pragmatis dan konstruktif dalam menumbuhkan kesadaran dan partisipasi masyarakat dalam turut mengelola lingkungan. Penelitian pengabdian masyarakat ini mempunyai tujuan untuk mengetahui strategi komunikasi lingkungan dalam menumbuhkan kesadaran masyarakat terhadap kebersihan sungai di kali Jagir.

\section{METODE PELAKSANAAN}

Penelitian ini menggunakan metode penelitian kualitatif dengan pendekatan deskriptif. Waktu pelaksanaan penelitian pada bulan April Sampai Juli 2020. Adapun tempat yang menjadi lokasi penelitian adalah Kampung Baru Jl.Bratang Tangkis. Alasan peneliti memilih lokasi ini karena adanya kebiasaan buruk masyarakat dan sekitarnya yang masih saja membuang sampah langsung ke sungai dan mencemari air serta lingkungannya seperti BAB ataupun mandi, cuci baju di sungai. Subjek penelitian berjumlah 8 informan yang dipilih dengan menggunakan teknik purposive. Pengumpulan data dilakukan melalui wawancara mendalam, observasi dan dokumentasi. Dalam hal ini peneliti melakukan wawancara dengan semua informan utama dan informan pendukung, Dalam observasi ini peneliti mengamati langsung obyek yang diteliti.

\section{HASIL DAN PEMBAHASAN}

Strategi komunikasi lingkungan team peneliti pengabdian masyarakat Stikosa-AWS di Kampung Baru jalan Bratang Tangkis.

Robert Cox dalam bukunya Environmental Communication and the Public Sphere, mengemukakan bahwa komunikasi lingkungan adalah sarana pragmatis dan konstitutif untuk memberikan pemahaman mengenai lingkungan kepada masyarakat, seperti halnya hubungan kita dengan alam semesta. Ini merupakan sebuah media simbolik yang digunakan untuk menciptakan masalah lingkungan dan negosiasi perbedaan respon terhadap permasalah 
lingkungan yang terjadi. Dengan kata lain komunikasi lingkungan digunakan untuk menciptakan kesepahaman mengenai permasalahan lingkungan (Cox, 2010:20).

Menurut Oepen, komunikasi lingkungan adalah rencana dan strategi melalui proses komunikasi dan produk media untuk mendukung efektivitas pembuatan kebijakan, partisipasi publik, dan implementasinya pada lingkungan (oepen. 1999:6). Dalam pengertian oepen dapat dipahami bahwa komunikasi lingkungan menjadi komponen yang terintegritas dalam kebijakan.

Program komunikasi seharusnya tidak sekedar berorientasi sumber dan media - centric belaka. Harus ada partisipasi besar dari penerima atau dari masyarakat. Program komunikasi lingkungan mutlak harus fokus memberdayakan audien, melibatkannya, dan bukan menempatkannya pada posisi yang pasif (Yenrizal, 2015:14). Menyangkut strategi Komunikasi lingkungan maka pesan dikemas dalam berbagai medium untuk menumbuhkan kesadaran dan partisipasi masyarakat dalam pengelolaan lingkungan. Komunikasi lingkungan tujuannya untuk menumbuhkan kesadaran dan partisipasi masyarakat dalam mengelola lingkungan yang bersifat dialogis, intensif dan lebih banyak terjadi pada komunikasi interpersonal dan komunikasi kelompok, bukan hanya sekedar menyediakan dan menyebarluaskan informasi lingkungan.

Team pengabdian masyarakat Stikosa-AWS berperan untuk mengumpulkan dan memobilisasi masyarakat dalam melakukan sosialisasi, sebagai sarana untuk mendidik masyarakat mengembangkan kesadaran dirinya untuk menunjang kebersihan air kali jagir di masyarakat sekitar. Team pengabdian masyarakat Stikosa-AWS berperan untuk mengumpulkan dan memobilisasi masyarakat sekitar kali jagir dalam melakukan sosialisasi, sebagai sarana untuk mendidik masyarakat mengembangkan potensi dirinya seperti dalam pengelolaan potensi lingkungan hingga menjadi sesuatu yang memiliki nilai ekonomis untuk menunjang ekonomi masyarakat.

Strategi komunikasi merupakan langkah awal dan menjadi penentu dalam bagaimana komunikasi lingkungan akan dijalankan. Oleh karena itu, perlu dipertimbangkan banyak hal dengan memperhitungkan faktor-faktor pendukung atau faktor yang menghalanginya dengan memperhitungkan dan memperhatikan tahapan dan langkah-langkah dalam strategi komunikasi lingkungan.

1.Tahap Assesment atau Penilaian Tahap penilaian, yang terdiri dari langkah analisis situasi dan identifikasi masalah, analisis pihak/pelaku yang terlibat, dan tujuan komunikasi. Analisis merupakan aktivitas untuk meneliti unsur-unsur pokok suatu proses atau gejala sehingga kita dapat mengenal dan mengakui kondisi mana yang memberikan kontribusi pada berfungsinya suatu unit dan kondisi mana yang menciptakan masalah pada unit yang diteliti (Yasir, 2011:65). Masalah yang terjadi pada lingkungan yaitu adanya kerusakan di daerah daratan pesisir akibat abrasi dan juga kurangnya kesadaran masyarakat dalam memahami kondisi lingkungannya, maka dibentuklah Kelompok Masyarakat Peduli Alam Sekitar untuk menjadi solusi dari penyelesaian permasalahan yang ada.

2.Tahap Perencanaan. Tahap perencanaan yang terdiri dari pengembangan strategi komunikasi, memotivasi dan memobilisasi masyarakat, dan pemilihan media. Strategi komunikasi dilakukan dengan memilih komunikator yang tepat. Team pengabdian masyarakat Stikosa-AWS melakukan kerjasama dan memberikan motivasi dengan masyarakat kampung baru kali jagir. Motivasi adalah kegiatan komunikasi dengan memberikan dorongan kepada seseorang atau diri sendri untuk mengambil tindakan yang dikehendaki (Yasir, 2011:44). Sosialisasi bertujuan untuk memotivasi masyarakat agar tumbuh kesadaran, kepedulian dan partisipasinya dalam program kesadaran pentingnya kebersihan kali jagir. 
3.Tahap Produksi Tahap produksi pesan yang terdiri dari langkah desain pesan dan produksi media. Pesan-pesan komunikasi lingkungan harus lebih diarahkan pada upaya mengubah kebiasaan yang tidak peduli terhadap lingkungan hidup. Pesan komunikasi lingkungan yang diproduksi sebaiknya memiliki kriteria memunculkan isu-isu lingkungan dan menyampaikan solusi dari masalah lingkungan. Kedua kriteria tersebut diharapkan mampu untuk menumbuhkan kesadaran masyarakat terhadap lingkungan (Asaad, 2014).

4.Tahap Aksi dan Refleksi Tahap aksi dan refleksi yang terdiri dari langkah penyebaran melalui media dan langkah dokumentasi, monitoring, dan evaluasi. Upaya penyadaran dan kepedulian masyarakat terhadap kebersihan air sungai jagir dan lingkungan sekitarnya melalui komunikasi lingkungan kuncinya ada pada prioritas dan komitmen masyarakat sekitar.

Kurangnya edukasi dan penyuluhan menyebabkan kebiasaan buruk ini terus menerus dilakukan. Maka dengan kondisi kampung yang menengah ke bawah dan tidak memiliki perangkat desa. Media yang team pengabdian masyarakat Stikosa-AWS kenakan berupa desain cetak. Jika dibanding dengan brosur yang nantinya akan dijatuhkan di sungai atau poster yang kecil yang dengan mudah di ambil. Maka dipilih berupa banner berukuran 2x1,5 meter dan 3x2 meter, akan memudahkan orang yang melintas akan melihat. Banner berisikan data mengenai banyaknya orang yang masih menggunakan sungai secara langsung seperti buang air besar (BAB), mandi dan cuci pakaian serta banyaknya sampah di sungai. Sedangkan di area sungai sudah dipasang plakat himbauan yang tidak dihiraukan. Tidak hanya itu, terdapat informasi baku mutu air sesuai PP No.82 Tahun 2001 tentang Pengelolaan Kualitas Air dan Pengendalian Pencemaran Air dari kelas I-IV. Dibarengi dengan data air Kali Jagir yang tidak sesuai dengan standart baku mutu kelas I. Dari data-data yang kami temukan, dijelaskan bahwa Kali Jagir termasuk baku mutu kelas II sehingga tercipta slogan "Ayo Jogo Kali! Agar layak sebagai air minum".

Pemasangan banner sudah dilakukan, langkah selanjutnya team pengabdian masyarakat Stikosa-AWS melakukan monitoring dan evaluasi melalui pemantauan pada area sungai dan wawancara ke beberapa warga untuk menanyakan pendapat tentang keberadaan banner komunikasi untuk kebersihan. Pada hari kedua monitoring dan wawancara dilaksanakan dan team pengabdian masyarakat Stikosa-AWS menerima saran dalam pemasangan banner yang lebih strategis, sehingga usai wawancara kami langsung eksekusi pemindahan tempat banner. Dan dalam pemantauan 3 hari ditemukan sedikit yang melakukan aktivitas buang air besar (BAB), mandi dan cuci-cuci di sungai dibanding saat observasi awal pra riset. Ditahap akhir kami memberikan sembako sebagai ucapan terima kasih telah membantu melancarkan kegiatan pengabdian masyarakat kami dan penyerahan cinderamata. 
Arkansyah dkk: Strategi Komunikasi Lingkungan Membangun Kesadaran Masyarakat Terhadap Kebersihan Sungai Jagir

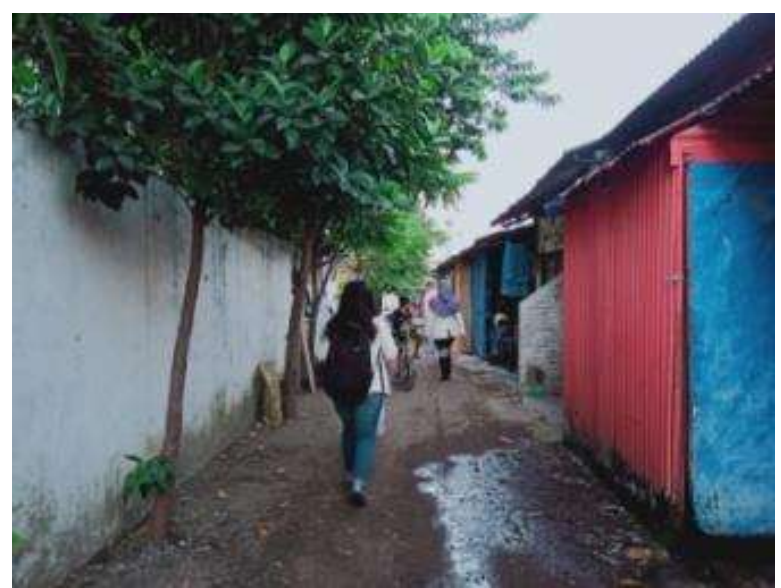

Gambar 1. Survei lokasi warga stren kali jagir

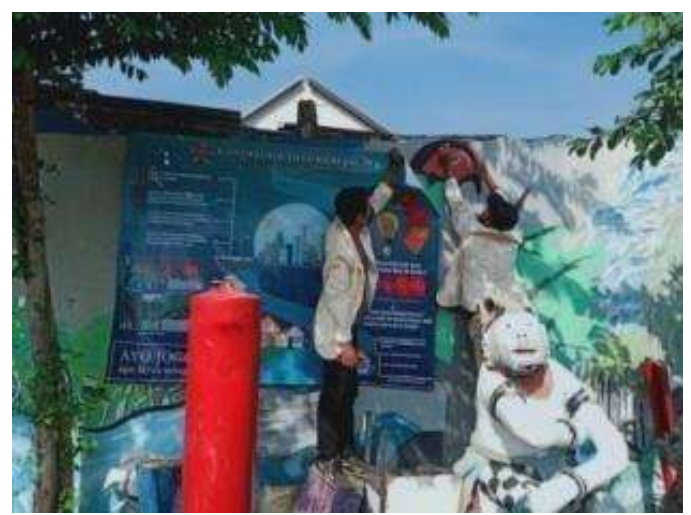

Gambar 2. Pemasangan banner infografis

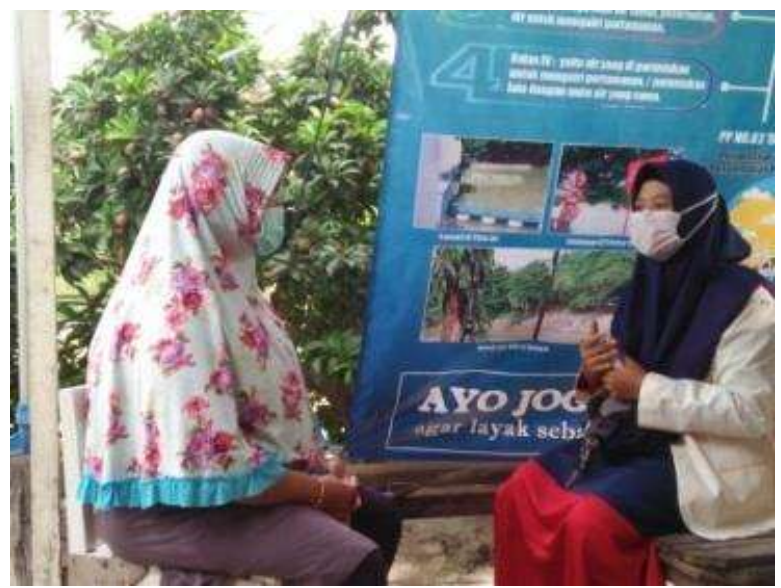

Gambar 3. Wawancara dan sosialisasi banner infografis 


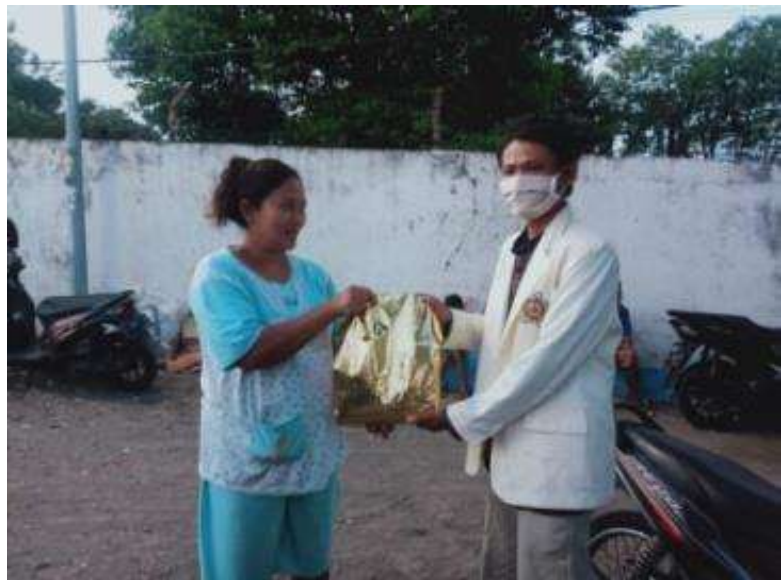

Gambar 4. Pemberian sembako

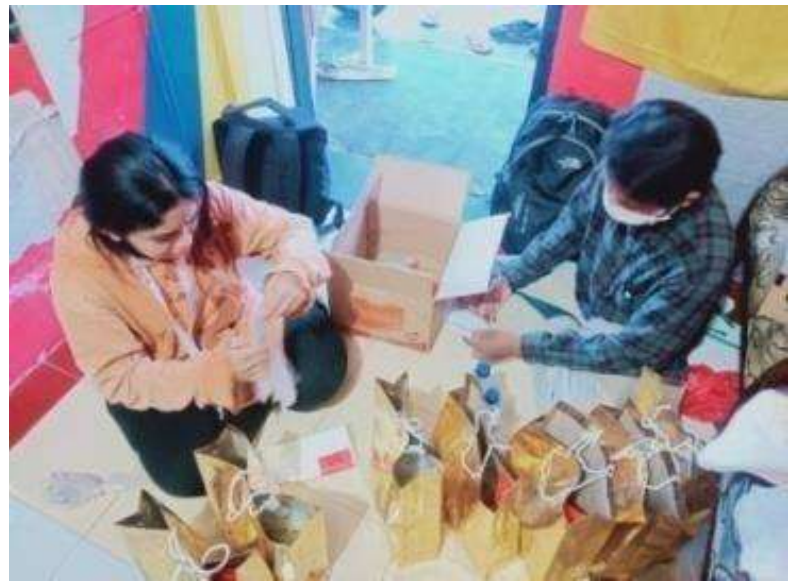

Gambar 5. Pembagian sembako

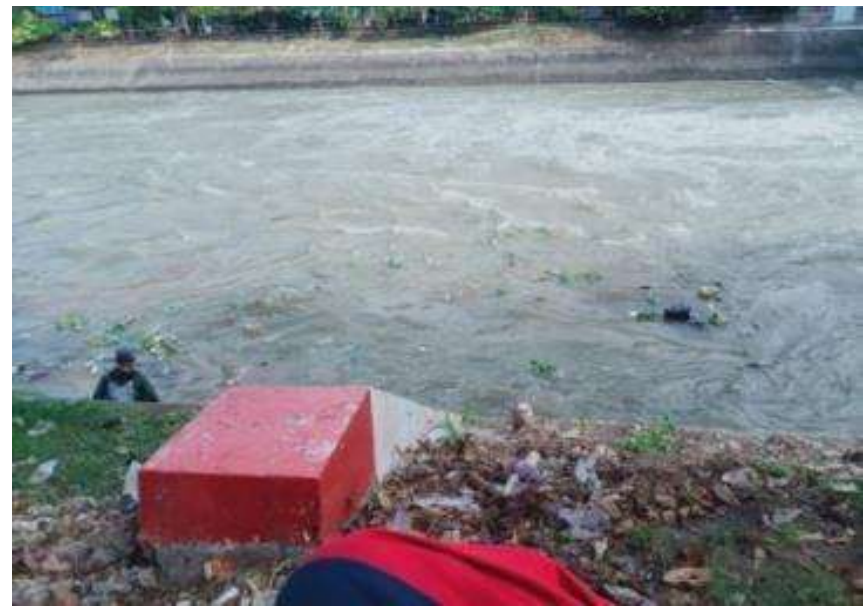

Gambar 6. Kondisi sungai Jagir terlihat bersih 


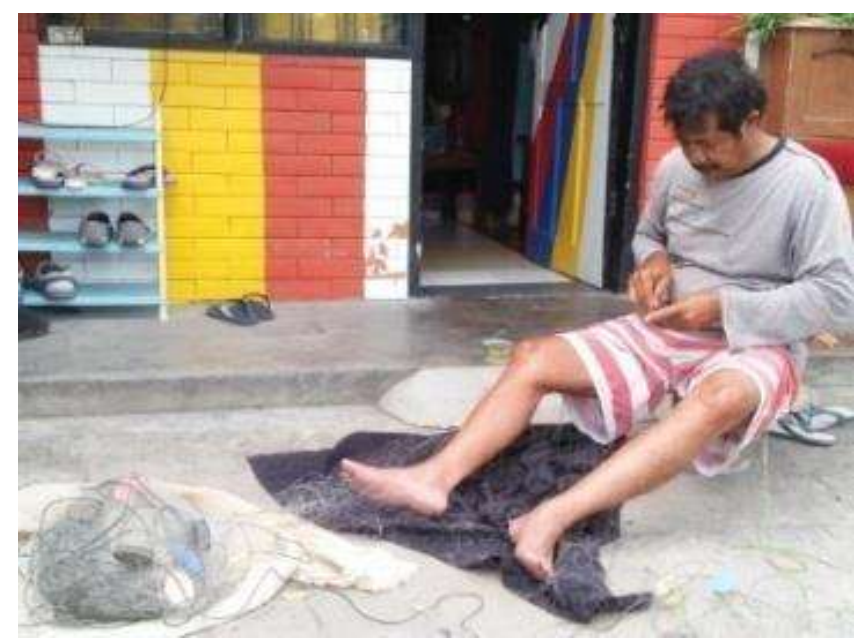

Gambar 7. Warga kali Jagir memancing

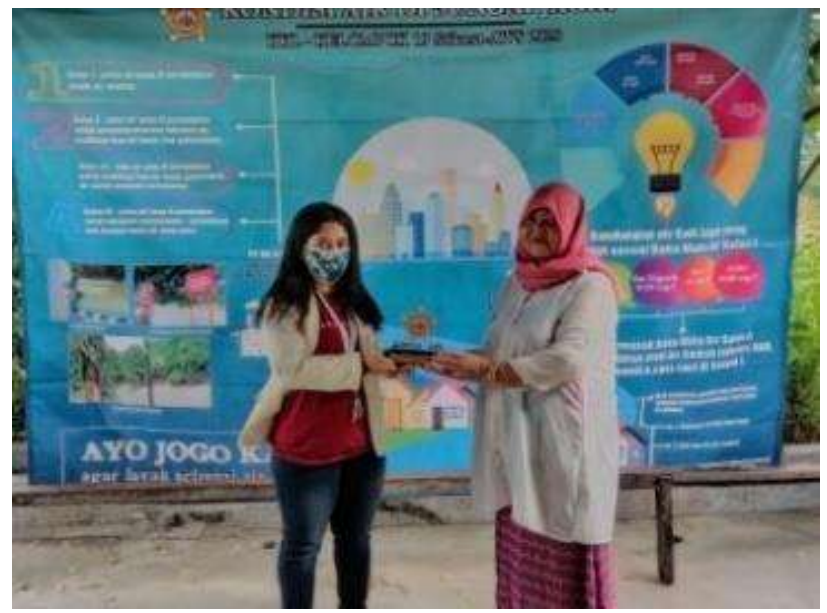

Gambar 8. Pemberian cinderamata Stikosa-AWS

\section{PENUTUP}

\section{Kesimpulan}

Berdasarkan penelitian yang telah dilakukan dan dianalisis, dengan permasalahan yang ada dan teknik analisis yang telah ditentukan, maka dapat diambil kesimpulan antara lain :

1. Strategi Komunikasi Lingkungan yang telah dilakukan team pengabdian masyarakat Stikosa-AWS yaitu melalui beberapa tahap. Pertama, tahap assesment/penilaian yang meliputi analisis situasi dan identifikasi masalah sosial, ekonomi, lingkungan, Analisis pihak/pelaku yang terlibat, Komunikasi obyektif (untuk meningkatkan pengetahuan, mempengaruhi/perilaku). Kedua, tahap perencanaan yang meliputi pengembangan strategi komunikasi, Memotivasi dan mobilisasi masyarakat, Pemilihan media. Ketiga, tahap produksi yang meliputi desain pesan yang akan disampaikan, Produksi media. Keempat, tahap pelaksanaan yang meliputi penyebaran melalui media dan implementasinya, dokumentasi dan evaluasi. 
2. Diperlukannya strategi komunikasi yang tepat agar tercapainya kesepahaman bersama (mutual understanding).

\section{Saran}

Berdasarkan hasil penelitian dan kesimpulan diatas, saran yang dapat penulis sampaikan yaitu: 1. Mempertahankan serta menguatkan kekompakan dilingkup internal kelompok warga peduli sungai sekitar melalui strategi komunikasi lingkungan untuk meningkatkan partisipasi masyarakat dan berbagai pihak lainnya.

2. Untuk penelitian selanjutnya lebih menekankan pada faktor pendorong kelompok masyarakat atau LSM suatu daerah dalam komunikasi lingkungan. Fokus pada strategi media yang digunakan dalam mengkomunikasikan program mereka ke pihak yang mau berkerjasama maupun ke kelompok masyarakat lain untuk ikut berpartisipasi dalam program lingkungan.

\section{DAFTAR PUSTAKA}

Sumber Buku :

Ambo Tuwo, 2011. Pengelolaan Ekowisata Pesisir dan Laut. Brilian Internasional: Surabaya.

Bengen, Dietrich. 2000. Pengelolaan Ekosistem Wilayah Pesisir. Pusat Kajian Sumberdaya Pesisir dan Lautan IPB: Bogor.

Bungin, Burhan. 2015. Komunikasi Pariwisata (Tourism Communication): Pemasaran dan Destinasi Edisi Pertama. Prenadamedia Group: Jakarta.

Cangara,Hafied. 2007. Pengantar Ilmu Komunikasi. Raja Grafindo Persada: Jakarta.

Fandeli, C. Mukhlison 2000. Pengusahaan Ekowisata. Fahutan UGM-UKSDA DIY -Pustaka Pelajar:Yogyakarta.

Flor, Alexander G. 2004, Environmental Communication : Principles, Approaches and Strategies of Communication, Applied to Environmental Management, University of the Philippines.

Ghufran H. Kordi, Ekosistem Mangrove, 2012. Potensi, Fungsi, dan Pengelolaan, cet.1. Rineka Cipta: Jakarta.

Hadiwijoyo, Suryo Sakti. 2012. Perencanaan Pariwisata Perdesaan Berbasis Masyarakat Sebuah Pendekatan Konsep. Graha Ilmu: Yogyakarta.

Mulyana, Deddy. 2016. Ilmu Komunikasi Suatu Pengantar. Remaja Rosdakarya: Bandung.

Oepen, Manfred and Hamacher, Winfried. 1999. Environmental Communication for Sustainable Development.

Robert, Cox. 2010, Environmental Communication And Public Sphere, SAGE Publication, Inc Yasir. 2011. Perencanaan Komunikasi. Pusat Pengembangan Universitas Riau: Pekanbaru.

Yenrizal. 2015. Komunikasi Lingkungan Masyarakat Petani Pedesaan, Studi Etnoekologi Komunikasi

Masyarakat Semende Darat Tengah, Muara Enim Sumatera Selatan, Disertasi, Pascasarjana FIKOM Universitas Padjadjaran: Bandung. 